\title{
Determination of 1,5-anhydro-glucitol- carrier protein conjugates by matrix-assisted laser desorption/ionization tof mass spectrometry and antibody formation
}

\author{
Li-Jiang Xuan ${ }^{\text {a }}$, Hiroyuki Tanaka ${ }^{\text {a }}$, Satoshi Morimoto ${ }^{\text {a }}$, Yukihiro Shoyama ${ }^{\text {a,*, }}$ \\ Hiroshi Akanuma ${ }^{\mathrm{b}}$ and Keiji Muraoka ${ }^{\mathrm{c}}$ \\ ${ }^{a}$ Department of Pharmacognosy, Graduate School of Pharmaceutical Sciences, Kyushu University, \\ Maidashi 3-1-1, Higashiku, Fukuoka 812-8582, Japan \\ ${ }^{\mathrm{b}}$ Department of Chemistry, College of Arts and Sciences, University of Tokyo, Meguroku, Tokyo 153, \\ Japan \\ ${ }^{\mathrm{c}}$ Higashichikushi Junior College, 5-1-1 Shimoitozu Kokurakita-ku, Kitakyushu, Japan
}

\begin{abstract}
In order to prepare the monoclonal antibody against 1,5-anhydro-glucitol (1), it was conjugated with bovine serum albumin (BSA), human serum albumin (HSA) or chicken lysozyme (CL) using succinate or $\beta$-alanine succinate as a spacer to produce individual antigen conjugates. The number of hapten contained in each antigen conjugate was determined by matrixassisted laser desorption/ionization tof mass (MALDI-tof-MS) spectrometry. The formation of monoclonal antibody (MAb) was also discussed.
\end{abstract}

\section{Introduction}

The 1-deoxy form of glucopyranose, 1,5-anhydro-glucitol (1), is one of the main polyols in cerebrospinal fluid and plasma [1]. The plasma levels of this cyclic polyol in most normal humans exceed those of glycerol and myo-inositol, two other major polyols in human body fluid. The level of plasma 1 has been shown to decrease not only sensitively but specifically in patients with diabetes mellitus [2-4]. Accordingly the concentration of plasma $\mathbf{1}$ can constitute a valuable clinical marker in the diagnosis and concern the therapy of diabetes. However, there is no simple and precise quantitative analytical method for plasma 1 except gas-liquid chromatography so far, which is tedious and time-consuming [5-7].

Since the first description by Köhler and Milstein in 1975 [8], monoclonal antibodies (MAbs) have played an increasingly important role in detecting higher molecular weight compounds. Recently, enzyme immunoassay systems using MAbs against naturally occurring biologically active compounds of small molecular weight have become an important methodology for studies on receptor binding analysis and quantitative and qualitative analysis because of their high affinity and specificity [9]. For formation of antibodies against compounds of low molecular weight, the synthesis of a hapten-carrier protein conjugate is necessary. The specificity of an immunoassay method is generally dependent on the site of linkage between hapten and protein moieties, moreover on the number of hapten in the antigen conjugate

\footnotetext{
*Corresponding author: Yukihiro Shoyama. Tel./Fax: +81 92642 6580; E-mail: shoyama@ shoyaku.phar.kyushu-u.ac.jp.
} 
[10]. However, there are no direct and appropriate analytical methods for hapten-carrier protein conjugate without involving differential UV spectrophotometric and radioactive methods. As we reported previously, MALDI-tof-MS were used routinely in our laboratory to confirm the formation and hapten enumeration of antigen conjugates for series of naturally occurring compounds, such as forskolin [11, 12], solamargine [13,15], marihuana compound [14], opium alkaloid [16,17] and crocin [18]. As a rapid, precise and direct analytical method in microscale, it can strategically be applied to the confirmation of many natural products and drugs, especially for these compounds having no specific UV absorbance, since the difficulties and ambiguities remain in the confirmation of antigen conjugate. Here we wish to present the preparation and hapten number determination of 1-carrier protein conjugates. Furthermore, the formation of MAbs against $\mathbf{1}$ is also discussed.

\section{Experimental}

\subsection{Chemicals and reagents}

${ }^{1} \mathrm{H}$ and ${ }^{13} \mathrm{C}$-NMR spectra were taken with Varian Unity-500P spectrometer. FAB-MS spectra were obtained with JEOL JMS-SX 102 spectrometer. Succinic anhydride, l-ethyl-3-(3-dimethyl aminopropyl) carbodiimide hydrochloride (EDC), $N$-hydroxysuccinimide (HOSu), bovine serum albumin (BSA), human serum albumin (HSA) and chicken lysozyme (CL) were provided by Nacalai Tesque (Kyoto, Japan). Complete and incomplete Freund's adjuvants (CFA and IFA) were obtained from Difco (Detroit, USA). MCI gel CHP-20P (75-150 $\mu \mathrm{m})$ was purchased from Mitsubishi Chemical Institutes, Ltd. (Tokyo, Japan). All other chemical and immunological reagents were standard commercial products of analytical grade.

\subsection{Synthesis of 1 hemisuccinate (2)}

A solution of $1(41 \mathrm{mg})$ and succinic anhydride $(175 \mathrm{mg})$ in anhydrous pyridine $(2.5 \mathrm{ml})$ was kept at $4^{\circ} \mathrm{C}$ overnight. After adding $\mathrm{H}_{2} \mathrm{O}(100 \mu \mathrm{l})$ for termination of the reaction, the solution was evaporated to dryness in vасио. 1 hemisuccinate $(\mathbf{2}, 43 \mathrm{mg})$ was afforded by chromatography on an MCI gel column using $\mathrm{MeOH}-\mathrm{H}_{2} \mathrm{O}$ as gradient eluent, and its structure was confirmed by spectroscopic method.

2, positive HRFAB-MS: $m / z 265.0927\left([\mathrm{M}+1]^{+}\right)$calcd. for $\mathrm{C}_{10} \mathrm{H}_{17} \mathrm{O}_{8}$ (theory 265.0293); ${ }^{1} \mathrm{H}-\mathrm{NMR}$ $\left(500 \mathrm{MHz}, \mathrm{D}_{2} \mathrm{O}\right): \delta 5.02(6-\mathrm{H}, \mathrm{dd}, J=1.8,11.7 \mathrm{~Hz}), 4.69(6-\mathrm{H}, \mathrm{dd}, J=6.4,11.7 \mathrm{~Hz}), 4.32(1-\mathrm{H}$, dd, $J=5.3,11.0 \mathrm{~Hz}), 4.14(1-\mathrm{H}, \mathrm{dd}, J=5.3,10.3 \mathrm{~Hz}), 4.06(4-\mathrm{H}, \mathrm{dd}, J=8.5,8.7 \mathrm{~Hz}), 3.95(3-\mathrm{H}$, $\mathrm{dd}, J=8.5,9.6 \mathrm{~Hz}), 3.89(5-\mathrm{H}, \mathrm{dd}, J=1.8,6.4 \mathrm{~Hz}), 3.62(2-\mathrm{H}, \mathrm{dd}, J=10.5,10.8 \mathrm{~Hz}), 2.85,2.84$ $\left(\mathrm{CH}_{2} \times 2, \mathrm{~m}\right) ;{ }^{13} \mathrm{C}-\mathrm{NMR}\left(125.7 \mathrm{MHz}, \mathrm{D}_{2} \mathrm{O}\right): \delta 179.7(\mathrm{COOH}), 177.4(\mathrm{COOR}), 80.4(\mathrm{C}-5), 80.0(\mathrm{C}-3)$, 72.3 (C-4), 72.0 (C-2), 71.6 (C-1), 66.5 (C-6), $31.6\left(\mathrm{CH}_{2} \times 2\right)$.

\subsection{Synthesis of activated 2}

$2(18 \mathrm{mg}), \mathrm{EDC}(27 \mathrm{mg})$ and HOSu $(17 \mathrm{mg})$ were dissolved in anhydrous DMF (1 ml) and stirred at $4{ }^{\circ} \mathrm{C}$ overnight. The solution was applied immediately in next conjugating step. 


\subsection{Synthesis of $\mathbf{2}-B S A$ conjugate (3)}

The activated reaction mixture above was added to a solution of BSA $(90 \mathrm{mg})$ in $50 \mathrm{mM}$ carbonate buffer ( $\mathrm{pH}$ 9.6), and it was stirred at $4^{\circ} \mathrm{C}$ for $24 \mathrm{~h}$. The reaction solution was dialyzed against water overnight, with the water changed for several times. After lyophilizing, 3 (96.7 mg) was obtained. 2HSA conjugate (4) and 2-CL conjugate (5) were synthesized in the same way.

\subsection{Synthesis of $\mathbf{2}-\beta$-alanine (6)}

$2(40 \mathrm{mg})$, EDC (43 mg) and HOSu (115 mg) were mixed in $2 \mathrm{ml}$ anhydrous DMF and stirred at room

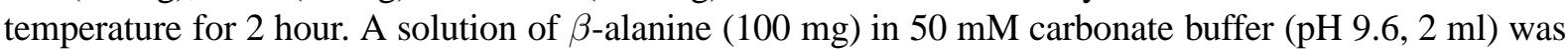
added and reacted for another 3 hour. The solution was chromatographed on an MCI gel column with $\mathrm{MeOH}-\mathrm{H}_{2} \mathrm{O}$ as gradient eluent. 2- $\beta$-alanine (6) was obtained as sodium salt. After transformation with cationic resin, $\mathbf{6}\left(40 \mathrm{mg}\right.$ ) was yielded, and the structure of $\mathbf{6}$ was confirmed by ${ }^{1} \mathrm{H}$ and ${ }^{13} \mathrm{C}$ NMR spectral analysis.

6, ${ }^{1} \mathrm{H}-\mathrm{NMR}\left(\mathrm{CD}_{3} \mathrm{OD}, 500 \mathrm{MHz}\right): \delta 4.36(\mathrm{H}-6, \mathrm{dd}, J=2.6,11.9 \mathrm{~Hz}), 4.16(\mathrm{H}-6, \mathrm{dd}, J=6.0,11.9$ $\mathrm{Hz}), 3.85(\mathrm{H}-1, \mathrm{dd}, J=5.4,11.1 \mathrm{~Hz}), 3.41(\mathrm{H}-1,4 ; \mathrm{m}), 3.34(\mathrm{H}-3, \mathrm{~m}), 3.25(\mathrm{H}-5, \mathrm{~m}), 3.14(\mathrm{H}-2$, m), 2.62, $2.48\left(\mathrm{CH}_{2} \times 4\right) ;{ }^{13} \mathrm{C}-\mathrm{NMR}\left(\mathrm{CD}_{3} \mathrm{OD}, 125.7 \mathrm{MHz}\right): \delta 175.9(\mathrm{COOH}), 174.3(\mathrm{CONHR}), 174.1$ (COOR), 79.9 (C-5), 79.8 (C-3), 71.7 (C-4), 71.3 (C-2), 71.0 (C-1), 65.3 (C-6), 36.8, 34.9, 31.4, 30.4 $\left(\mathrm{CH}_{2} \times 4\right)$.

\subsection{Synthesis of $6-B S A$ conjugate (7)}

$6(20 \mathrm{mg})$ was activated in the same way as 2 with EDC $(18 \mathrm{mg})$ and $\mathrm{HOSu}(10.5 \mathrm{mg})$ in DMF $(1 \mathrm{ml})$.

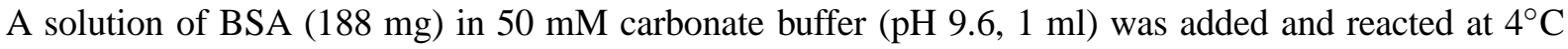
overnight. After dialyzing and lyophilizing, 6-BSA conjugate $(7,90 \mathrm{mg})$ was afforded. 6-HSA conjugate (8) was synthesized in the same way.

\subsection{Determination of hapten numbers by MALDI-tof-MS}

A small amount of antigen conjugate (1-10 pmol) was mixed with a $10^{3}$-fold molar excess of sinapinic acid in an aqueous solution containing $10 \%$ trifluroacetic acid. The mixture was subjected to a JMSELITE MALDI-TOF mass monitor and irradiated with a $\mathrm{N}_{2}$ laser ( $337 \mathrm{~nm}, 3 \mathrm{~ns}$ pulse). The ion formed by each pulse were accelerated by $25 \mathrm{kV}$ potential into a $1.7 \mathrm{~m}$ evacuated tube and detected using an IBM PC compatible computer.

\subsection{Immunization and hybridization}

A solution of 4 or $7(50 \mu \mathrm{g})$ in phosphate buffered saline (PBS, $250 \mu \mathrm{l})$ was emulsified with equal volume of CFA, then injected intraperitoneally to a 7-week-old BALB/C female mouse. Two weeks later the second injection was held with IFA instead of CFA. After several injections every two weeks, the last boosting injection was carried out intravenously with a solution of antigen $(50 \mu \mathrm{g})$ in PBS $(100 \mu \mathrm{l})$. Three days later, the splenocyte was isolated and fused with a HAT-sensitive mouse myeloma cell line, P3-X63-Ag8-653, by the polyethylene glycol (PEG) method [19]. Hybridomas producing MAb against 1 were cloned by the limited dilution method [20]. Established hybridomas were cultured in 5\% FCS eRDF medium. 


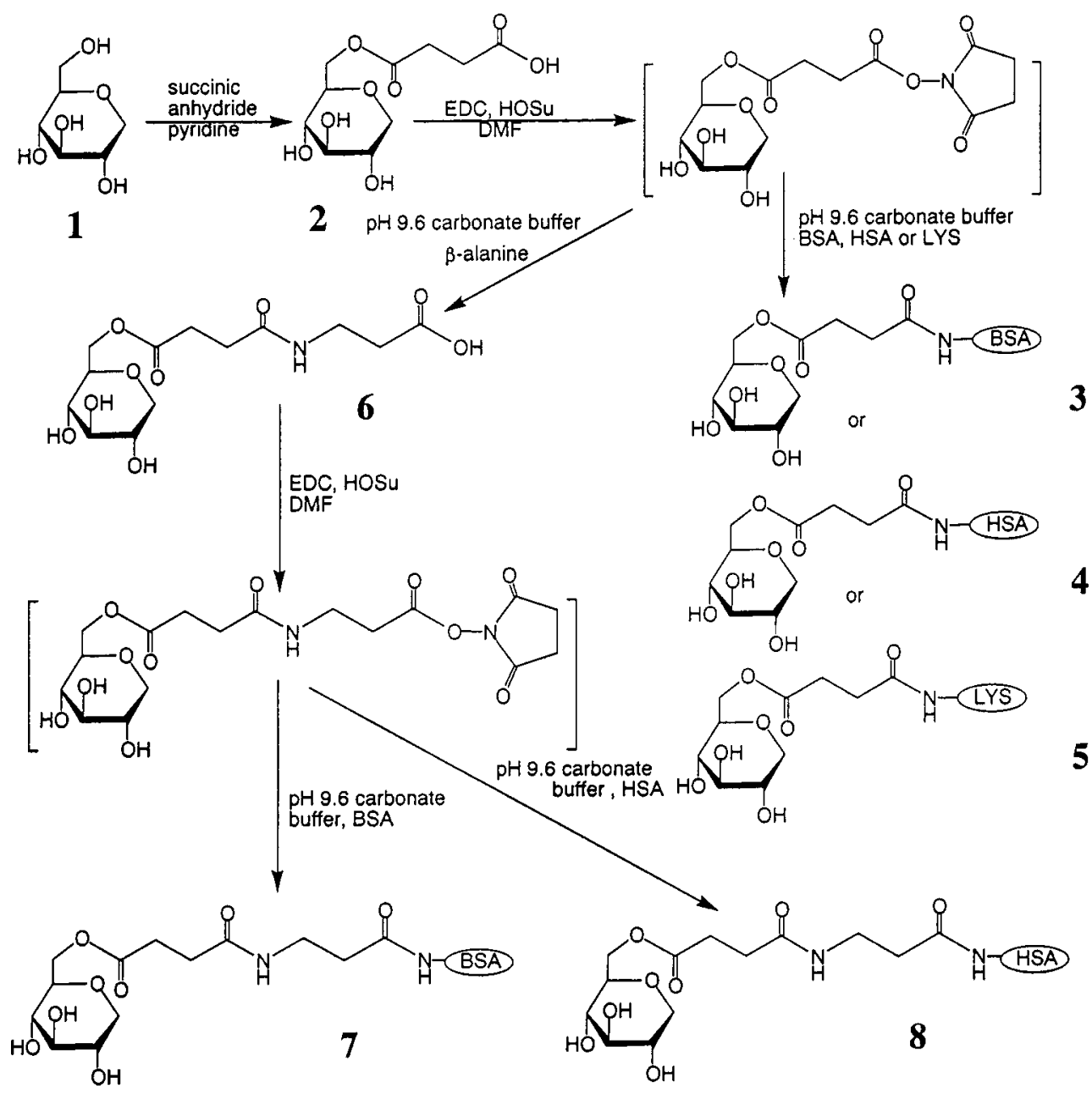

Fig. 1. Synthetic pathways of 1,5-anhydro-glucitol-carrier protein conjugates.

\subsection{Directive and competitive ELISA}

The reactivity of samples or MAbs to 1-carrier protein conjugate was determined by directive ELISA. A 96-well immunoplate (NUNC, Roskilde, Denmark) adsorbed by $100 \mu \mathrm{l}$ of $1 \mu \mathrm{g} / \mathrm{ml} 5$ or 8 in $50 \mathrm{mM}$ carbonate buffer ( $\mathrm{pH}$ 9.6) was treated with $300 \mu$ PBS containing $0.2 \%$ gelatin (G-PBS) for $1 \mathrm{~h}$ to reduce nonspecific adsorption. The plate was washed with PBS containing 0.05\% Tween 20 (T-PBS) and reacted with $100 \mu \mathrm{l}$ samples or MAbs for $1 \mathrm{~h}$. The plate was washed with T-PBS for three times, and then the plate was incubated with $100 \mu \mathrm{l}$ 2000-time-diluted peroxidase-labeled goat antimouse IgG (Organon Teknika Cappel Products, Westchester, USA) for $1 \mathrm{~h}$. With the plate washed by T-PBS for three times, $100 \mu \mathrm{l}$ substrate solution, $0.3 \mathrm{mg} / \mathrm{ml}$ 2,2-azino-bis(3-ethylbenzo-thiazoline-6-sulfonic acid) diammonium salt (ABTS) (Wako, Osaka, Japan) in $0.1 \mathrm{M}$ citrate buffer ( $\mathrm{pH} \mathrm{4.0)} \mathrm{containing} 0.006 \%$ $\mathrm{H}_{2} \mathrm{O}_{2}$, were added to each wells and incubated for $20 \mathrm{~min}$. Absorbance at $405 \mathrm{~nm}$ was measured with a FAR400 electrophotometer (SLT-LABINSTRUMENTS, Salzburg, Austria) using $490 \mathrm{~nm}$ as reference. All the reactions were preceded at $37^{\circ} \mathrm{C}$. Competitive ELISA was carried out in the similar way except that the MAb was co-incubated with free protein. 


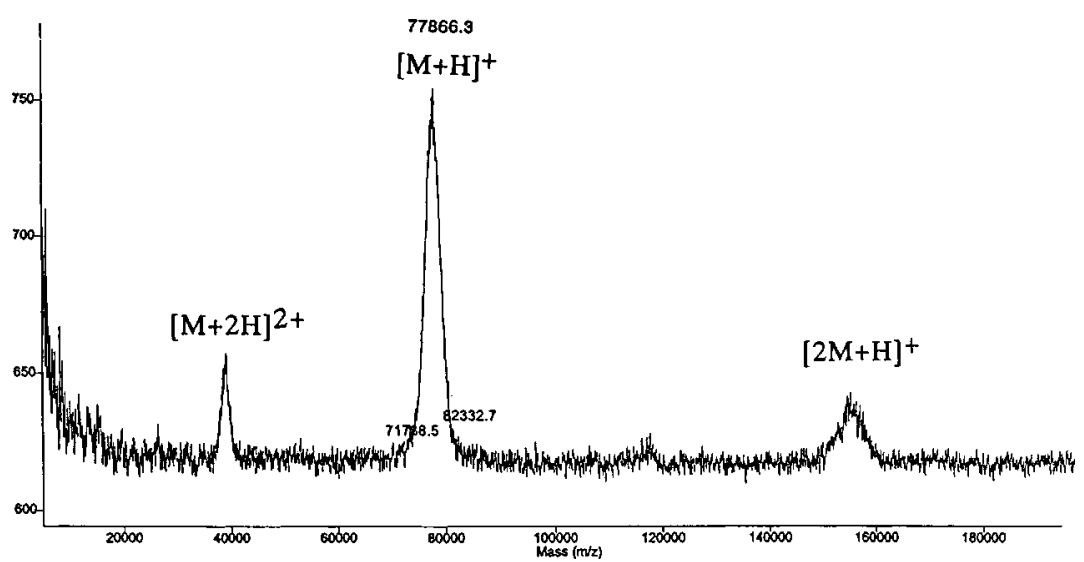

Fig. 2. MALDI-tof-MS spectrum of 1,5-anhydro-glucitol-HSA conjugate (4). $[\mathrm{M}+\mathrm{H}]^{+}$was indicated as the molecular ion, while $[\mathrm{M}+2 \mathrm{H}]^{2+}$ and $[2 \mathrm{M}+\mathrm{H}]^{+}$as the double charged and double massed ions, respectively.

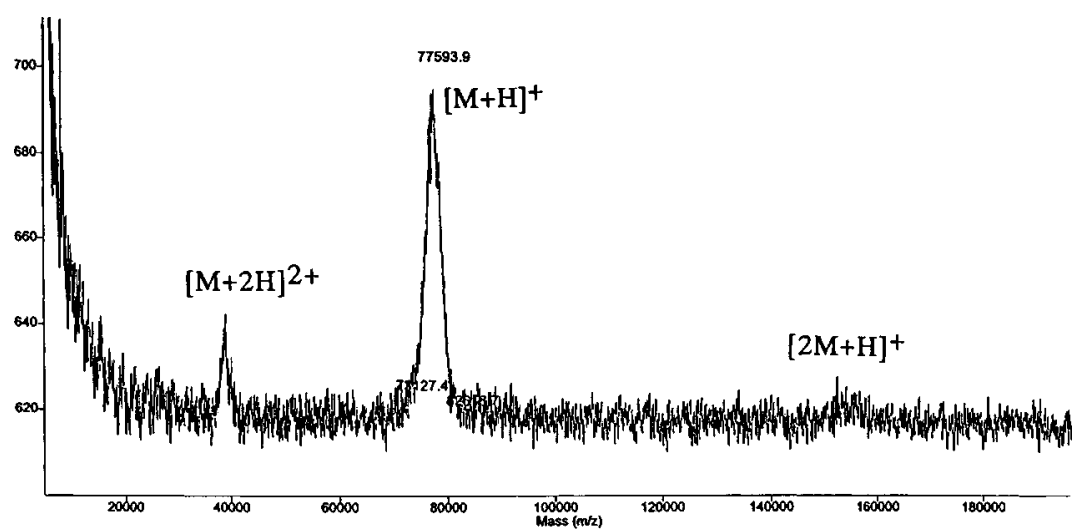

Fig. 3. MALDI-tof-MS spectrum of 1,5-anhydro-glucitol-BSA conjugate $(\mathbf{3}) .[\mathrm{M}+\mathrm{H}]^{+}$was indicated as the molecular ion, while $[\mathrm{M}+2 \mathrm{H}]^{2+}$ and $[2 \mathrm{M}+\mathrm{H}]^{+}$as the double charged and double massed ions, respectively.

Table 1

Hapten numbers of 1,5-anhydro-glucitol-carrier protein conjugates

\begin{tabular}{clccc}
\hline Conjugate & Spacer & Mass of hapten & {$[\mathrm{M}]^{+}$} & Hapten number \\
\hline $\mathbf{4}$ & succinate & 246 & 77866.3 & 46 \\
$\mathbf{3}$ & succinate & 246 & 77593.9 & 45 \\
$\mathbf{8}$ & $\beta$-alanine succinate & 345 & 70466.1 & 12 \\
$\mathbf{7}$ & $\beta$-alanine succinate & 345 & 71078.6 & 14 \\
$\mathbf{5}$ & succinate & 246 & 16474.0 & 9 \\
\hline
\end{tabular}

\section{Results and discussion}

Although it is difficult to predict epitopes targeted by the humoral response, the attachment site of hapten to the carrier protein should be considered as the determinant of antibody speciality. For 1, it is important to keep the coupling site far away from 1-methylene, which is the only distinguishable property to glucopyranose. As the synthetic pathway showed in Fig. 1, the proteins were selectively attached to 


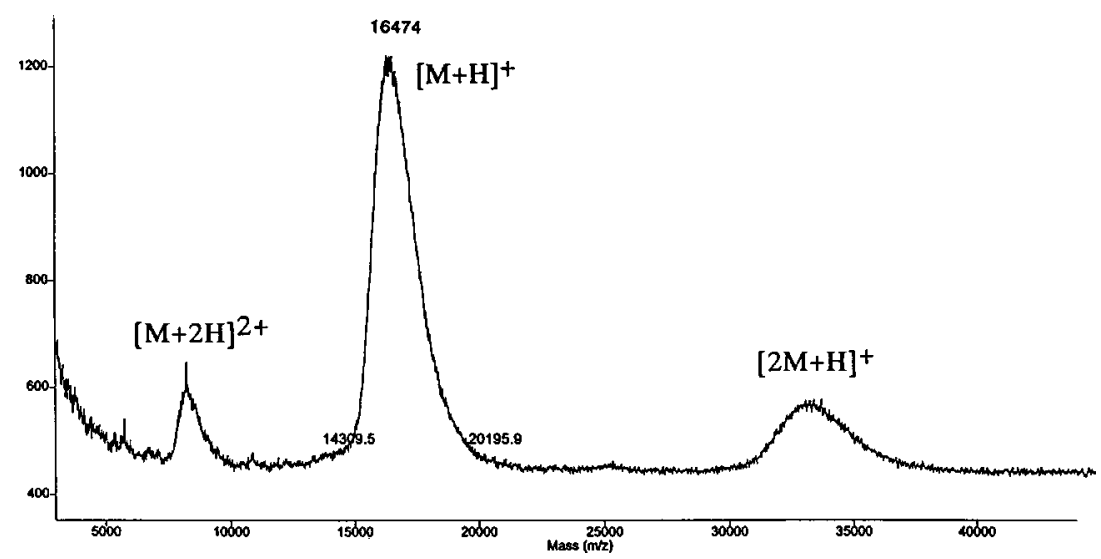

Fig. 4. MALDI-tof-MS spectrum of 1,5-anhydro-glucitol-chicken lysozyme conjugate $(\mathbf{5}) \cdot[\mathrm{M}+\mathrm{H}]^{+}$was indicated as the molecular ion, while $[\mathrm{M}+2 \mathrm{H}]^{2+}$ and $[2 \mathrm{M}+\mathrm{H}]^{+}$as the double charged and double massed ions, respectively.

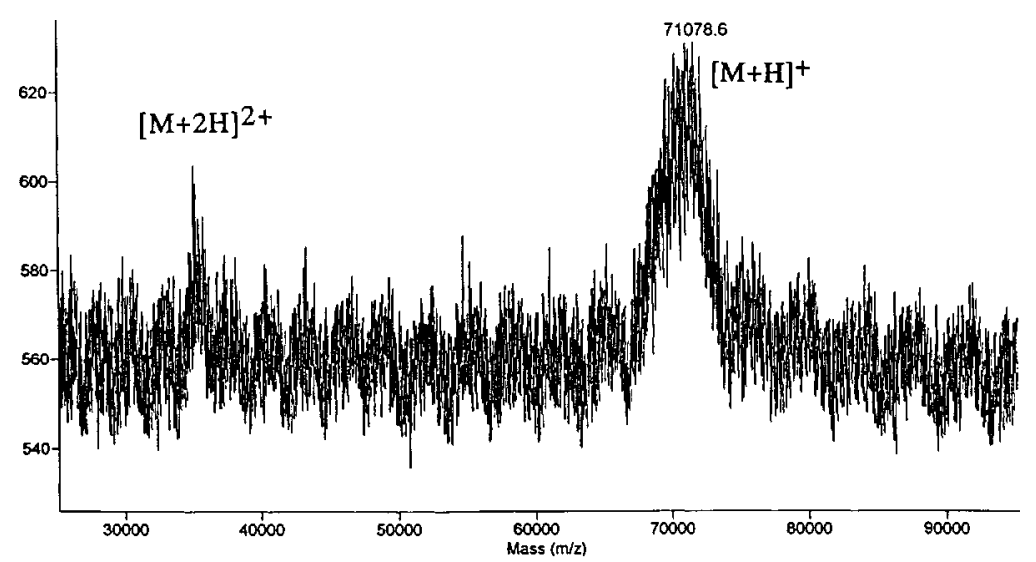

Fig. 5. MALDI-tof-MS spectrum of 1,5-anhydro-glucitol- $\beta$-alanine-BSA conjugate $(7) .[\mathrm{M}+\mathrm{H}]^{+}$was indicated as the molecular ion, while $[\mathrm{M}+2 \mathrm{H}]^{2+}$ as the double charged ions.

6-OH, which was considered as the optimal site. Succinate or succinate $\beta$-alanine was applied as a spacer to adjust the length between hapten and protein, which was considered as another important determinant for the specific binding of antibody. Different proteins conjugated with $\mathbf{1}$ are necessary in the screening procedure to reduce non-specific binding. The structures of individual intermediates were confirmed by FAB mass, ${ }^{1} \mathrm{H}-\mathrm{NMR}$ and ${ }^{13} \mathrm{C}$-NMR spectra, respectively (see Experimental).

In order to confirm the conjugation and hapten enumeration in the synthetic antigen conjugates, a small amount of 1-carrier protein conjugates were mixed with a $10^{3}$-fold molar excess of sinapinic acid in an aqueous solution containing trifluoroacetic acid and analyzed by MALDI-tof-MS using the calculated molecular mass of 66,431 for BSA as an external calibration standard. This method allows for rapid analysis of protein samples in the level of $1 \mathrm{pM}$.

As the MALDI-tof-MS spectrum of $\mathbf{4}$ shown in Fig. 2, a sharp peak appeared at $m / z 77,866.3$ together with the double-charged and the double-massed molecule ion of the intact conjugate, indicating that the molecular mass of $\mathbf{4}$ is 77,866.3. Using the molecular mass of 66,472 for HSA, the calculated mass of 1 moieties (246) is determined as 11,394. From this result, 46 moles of $\mathbf{1}$ were conjugated with the protein. 


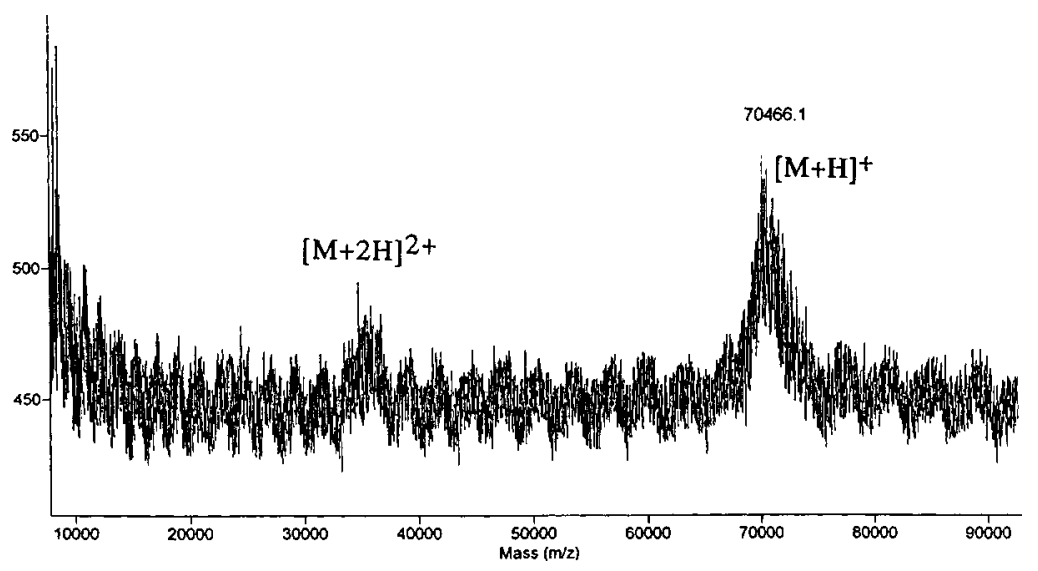

Fig. 6. MALDI-tof-MS spectrum of 1,5-anhydro-glucitol- $\beta$-alanine-HSA $(\mathbf{8}) \cdot[\mathrm{M}+\mathrm{H}]^{+}$was indicated as the molecular ion, while $[\mathrm{M}+2 \mathrm{H}]^{2+}$ as the double charged ions.

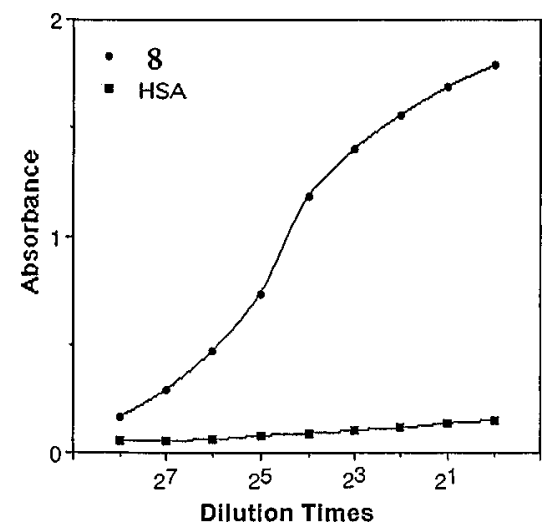

Fig. 7. Reactivity of monoclonal antibody against 1,5 -anhydro-glucitol- $\beta$-alanine-HSA (8) and HSA. Different times dilution of hybridoma culture supernatant were added to 96-well immunoplate precoated with $1 \mu \mathrm{g} / \mathrm{ml}$ 1,5 -anhydro-glucitol- $\beta$-alanine-HSA (8) or HSA. The plate was incubated with peroxidase labeled goat antimouse $\operatorname{lgG}$ and then treated with substrate.

Figure 3 showed the MALDI-tof-MS spectrum of $\mathbf{3}$, which is similar to that of $\mathbf{4}$. As indicated in Table 1, 45 moles of $\mathbf{1}$ were coupled to the protein in coincidence with the mass difference between BSA and 3. In these two cases, the conjugation of 1 with the protein occurred almost completely, since 60 lysine residues are contained in BSA or HSA, and some of them are difficult to react to 2 owing to stereochemical interaction.

A broader peak of $\mathbf{5}$ appeared compared to those of $\mathbf{4}$ and $\mathbf{3}$ as indicated in Fig. 4. This phenomenon clearly shows that $\mathbf{5}$ is unhomogenous depending on hapten numbers. The peak of $\mathbf{5}$ is at $\mathrm{m} / z \mathbf{z}, 474$, indicating that the differences of molecular mass between $\mathbf{5}$ and CL are 2,177 using a molecular mass of 14,297 for CL. From this, 8.8 molecules of $\mathbf{5}$ combined with CL as indicated in Table 1.

The spectra of $\mathbf{7}$ and $\mathbf{8}$ were shown in Figs 5 and 6. The peaks are broader compared with those of $\mathbf{4}$ and $\mathbf{3}$ (Figs 2 and 3). Furthermore, the hapten numbers are clearly smaller in comparison of those of $\mathbf{4}$ and $\mathbf{3}$, resulting in 12 and 14 moles, respectively, by the same determination method as $\mathbf{4}$, as indicated in Table 1. The reason of these differences is obscure. 
The splenocytes immunized by 4 or 7 individually were fused with P3-X63-Ag8-653 myeloma cell by PEG as we reported previously $[11,13,17]$. After HAT selection and the single cell cloning by the limited dilution method, several hybridomas producing MAb against 1-carrier protein conjugate were obtained. The directive ELISA used the MAb can specifically react to 1 moiety, as showed in Fig. 7. However, the competitive ELISA indicated the affinity to free $\mathbf{1}$ is very low. It is suggested that $\mathbf{1}$ molecule may be too small for the epitope area, and how to increase the affinity to free $\mathbf{1}$ is in progress.

\section{Acknowledgement}

The research in this paper was supported in part by a Grant-in-Aid for Scientific Research from the Ministry of Education, Science and Culture of Japan.

\section{References}

[1] T. Yamanouchi, Y. Tachibanna, H. Akanuma, S. Minoda, H. Shinohara, H. Moromizato and I. Akaoka, Am. J. Physiol. 263 (Endocrinol. Metan. 26) (1992), E268.

[2] M. Morita and H. Akanuma, J. Biochem. 112 (1992), 385.

[3] T. Yamanouchi, H. Akanuma, F. Takaku and Y. Akanuma, Diabetes 35 (1986), 204.

[4] S. Kametani, Y. Hashimoto, T. Yamanouchi, Y. Akanuma and H. Akanuma, J. Biochem. 102 (1987), 1599.

[5] Yoshioka, S. Satoh, T. Fujisawa, A. Fujimori, O. Takatani and M. Funabashi, Clin. Chem. 28 (1992), 1283.

[6] O.M. Pitkanen, Scand. J. Clin. Invest. 42 (1992), 445.

[7] T. Yamanouchi, H. Akanuma, T. Asano, C. Konishi, I. Akaoka and Y. Akanuma, Diabetes 36 (1987), 709.

[8] G. Köhler and C. Milstein, Nature 256 (1975), 495.

[9] W. Weiler, Chemistry of Plant Protection, Springer-Verlag, Berlin, 1990, p. 145.

[10] O.N. Chappey, P. Sandouk and J. Scherrmann, Immunol. Res. (1992), 1375.

[11] R. Sakata, Y. Shoyama and H. Murakami, Cytotechnology 16 (1994), 1001.

[12] Y. Shoyama, R. Sakata, R. Isobe and H. Murakami, Org. Mass Spectr. 28 (1993), 987.

[13] M. Ishiyama, Y. Shoyama, H. Murakami and H. Shinohara, Cytotechnology 18 (1996), 153.

[14] H. Tanaka, Y. Goto and Y. Shoyama, J. Immunoassay 17 (1996), 321.

[15] H. Tanaka, W. Putalun, C. Tsuzaki and Y. Shoyama, FEBS Lett. 404 (1997), 279.

[16] Y. Shoyama, T. Fukada and H. Murakami, Cytotechnology 19 (1996), 55.

[17] Y. Shoyama, T. Fukada, T. Tanaka, A. Kusai and K. Nojima, Biol. Pharm. Bull. 16 (1993), 1051.

[18] J. Xuan, H. Tanaka, Y. M. Xu and Y. Shoyama, Cytotechnology 29 (1998), 56.

[19] G. Galfre and C. Milstein, Methods Enzymol. 73 (1981), 3.

[20] W. Goding, J. Immunol. Meth. 39 (1980), 285. 


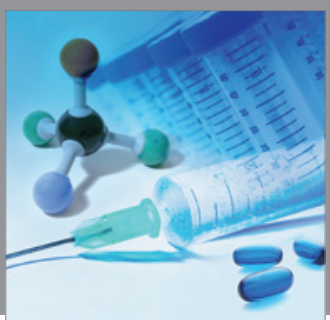

International Journal of

Medicinal Chemistry

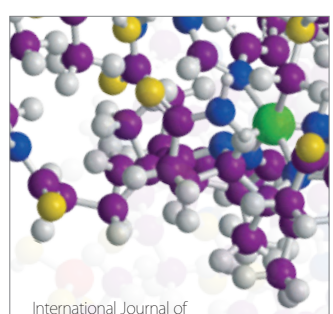

Carbohydrate Chemistry

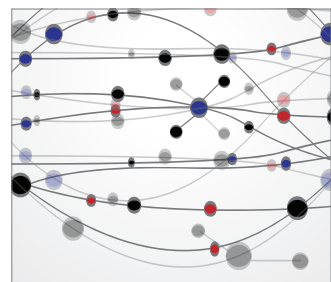

The Scientific World Journal
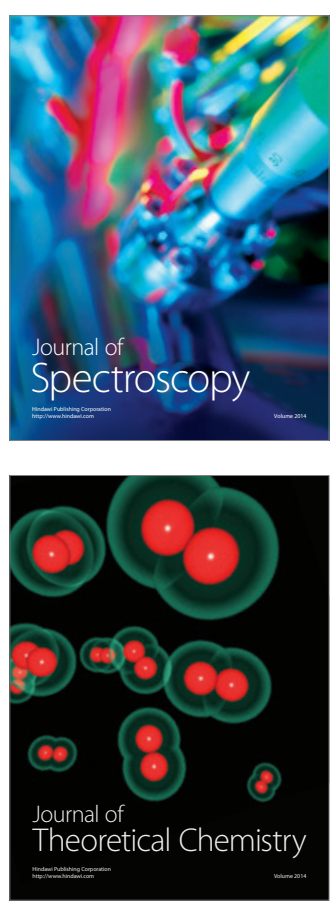
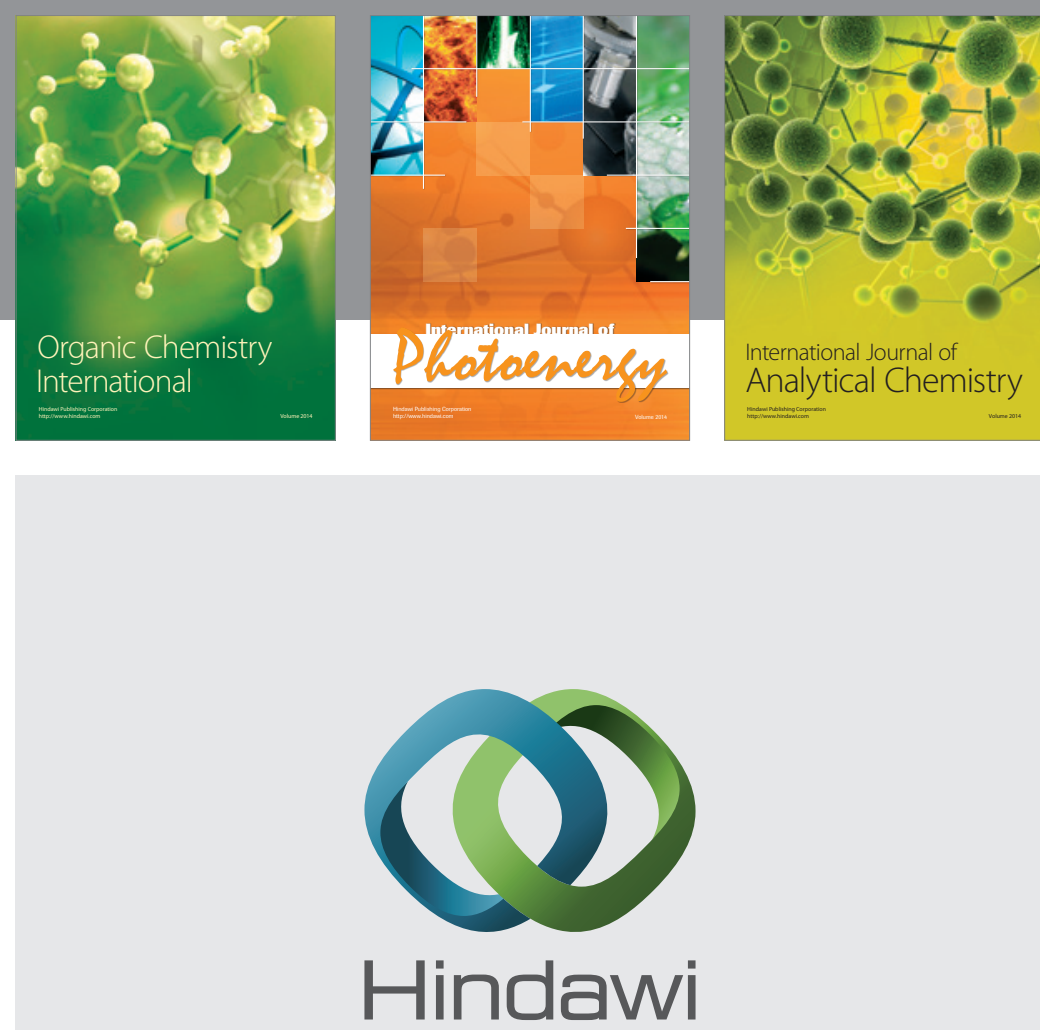

Submit your manuscripts at

http://www.hindawi.com
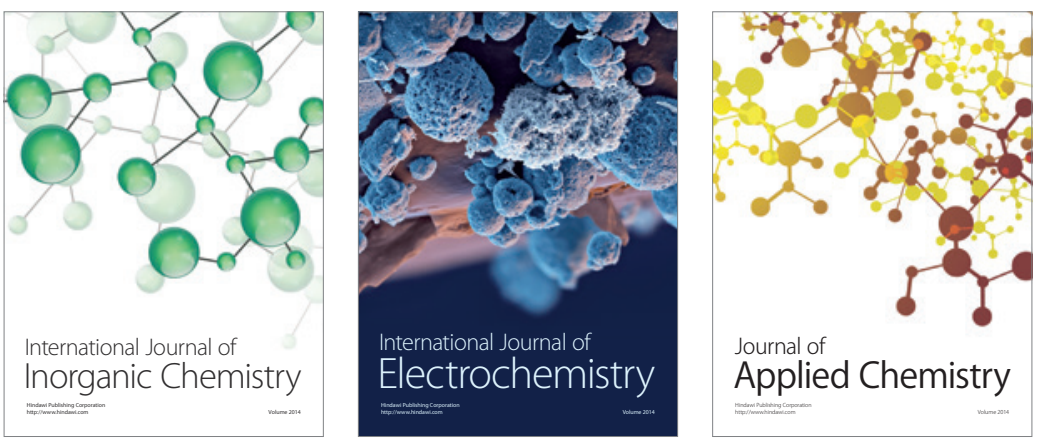

Journal of

Applied Chemistry
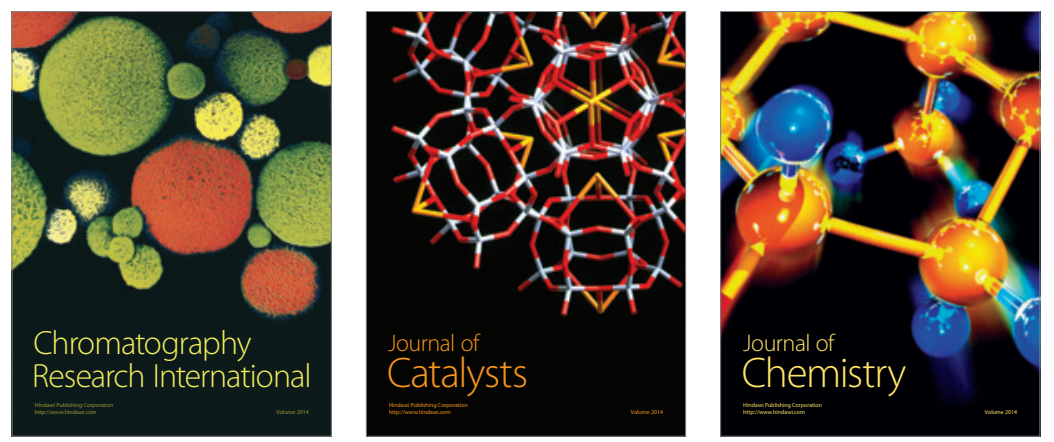
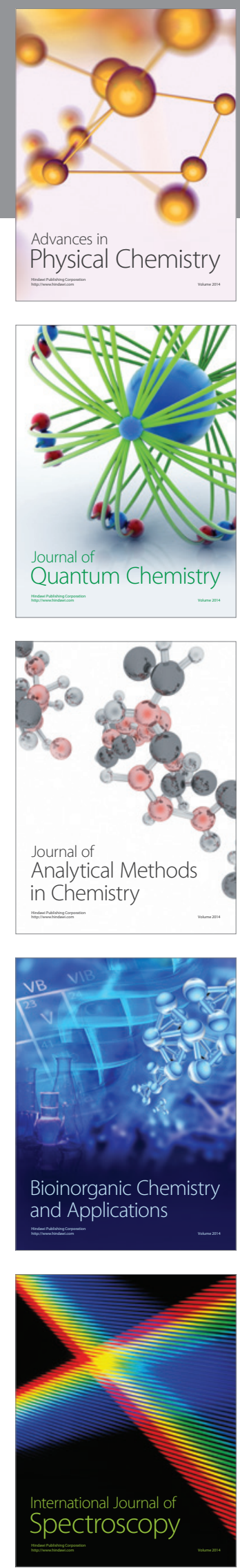